\title{
Carotid Cavernous Fistula: An Easily Missed Complication of Blunt Traumatic Brain Injury
}

\author{
Saptarshi Biswas ${ }^{1}$, Arpit Amin², Ashley Graziano ${ }^{3}$, Shekhar Gogna ${ }^{4}$
}

\begin{abstract}
A carotid cavernous fistula (CCF) is an abnormal vascular connection between the carotid arterial system and the cavernous sinus. Traumatic head injury, particularly basilar skull fractures, can result in a type A CCF. Type A CCFs are direct, high-flow shunts between the internal carotid artery and the cavernous sinus. Significant neuro-ophthalmologic sequela can result from such connections, including visual loss. These fistulas are commonly missed on the routine imaging completed following head trauma. If suspected, a cerebral angiography is the gold standard imaging modality, with endovascular coiling being the preferred treatment. Physicians should have a high index of suspicion for CCFs in trauma patients presenting with basilar skull fractures. Prompt recognition and treatment can resolve symptoms and prevent permanent sequela.
\end{abstract}

Keywords: Blunt trauma, Carotid cavernous fistula, Head injury.

Panamerican Journal of Trauma, Critical Care \& Emergency Surgery (2019): 10.5005/jp-journals-10030-1238

\section{RESUMEN}

Una fístula cavernosa carotídea (CCF) es una conexión vascular anormal entre el sistema arterial carotídeo y el seno cavernoso. La lesión traumática de la cabeza, particularmente las fracturas del cráneo basilar, pueden dar como resultado un CCF tipo A. Los CCF tipo A son derivaciones directas de flujo alto entre la arteria carótida interna y el seno cavernoso. Secuelas neuro-oftalmológicas importantes pueden ser el resultado de tales conexiones, incluida la pérdida visual. Estas fístulas se pasan por alto con frecuencia en las imágenes de rutina completadas después de un traumatismo craneal. Si se sospecha, una angiografía cerebral es la modalidad de imagenología estándar, siendo el tratamiento preferido la inserción endovascular. Los médicos deberían tener un alto índice de sospecha de fístulas cavernosas carotídeas en pacientes con trauma que presenten fracturas de cráneo basales. El reconocimiento y el tratamiento oportunos pueden resolver los síntomas y prevenir la secuela permanente.

Palabras clave: Fístula cavernosa carotídea, Lesión en la cabeza, Traumatismo cerrado.

\section{INTRODUCTION}

A carotid cavernous fistula (CCF) is an abnormal vascular connection between the carotid arterial system and the cavernous sinus. CCFs may be classified by etiology (spontaneous or acquired), anatomy (direct or dural), or hemodynamics (high or low flow). The angiographic classification by Barrow et al. defines the architecture of the lesion. This classification helps in therapeutic planning. Table 1 depicts the Barrow classification of carotid cavernous fistulas. Up to $70-90 \%$ of CCF occurs after trauma including blunt trauma to the skull; it is cited in the literature that CCF is more likely to develop after closed head injuries. ${ }^{2}$ Traumatic CCFs are almost exclusively type $A$, which are direct, high-flow shunts between the internal carotid artery and the cavernous sinus. Trauma, particularly basilar skull fractures, causes a rent in the intracavernous portion of the internal carotid artery (ICA) allowing arterial blood to enter the venous system of the cavernous sinus and its tributaries, the orbital venous complex, and the inferior petrosal sinus. CCFs can present with a variety of symptoms including headache, blurred vision, diplopia, proptosis, conjunctival chemosis, subjective bruits, and blindness. Many lesions are associated with significant neuro-ophthalmologic morbidity and mortality, making prompt recognition and treatment paramount. ${ }^{3}$ In this report, we present a case of traumatic CCF in a patient with a basilar skull fracture.

\section{Case Report}

A 26-year-old female initially presented with symptoms of headache and diplopia after a motor vehicle rollover accident where she was
${ }^{1}$ Department of Trauma and Acute Care Surgery, Forbes Regional Hospital, Allegheny Health Network, Pennsylvania, USA

${ }^{2}$ Department of Liver Transplantation, University of California, Los Angeles, California, USA

${ }^{3}$ Lake Erie College of Osteopathic Medicine (LECOM), Erie, Pennsylvania, USA

${ }^{4}$ Department of General Surgery, Westchester University Medical Center, Valhalla, New York, USA

Corresponding Author: Saptarshi Biswas, Department of Trauma and Acute Care Surgery, Forbes Regional Hospital, Allegheny Health Network, Pennsylvania, USA, Phone: 412-858-2000, e-mail: saptarshi biswas@comcast.net

How to cite this article: Biswas S, Amin A, et al. Carotid Cavernous Fistula: An Easily Missed Complication of Blunt Traumatic Brain Injury. Panam J Trauma Crit Care Emerg Surg 2019;8(1):61-63.

Source of support: Nil

Conflict of interest: None

a seat-belted driver. She was admitted at an outside hospital for 1 week with complaints of dizziness, headache, and double vision. She presented at our hospital with worsening symptoms of left-sided headache, blurry vision with diplopia, photophobia, dizziness, drooping of her left eyelid, and progressive inability to open her left eye for the previous 2-3 days. She had no symptoms of "floaters" or "flashes."

On physical examination, she was a healthy young woman, who was afebrile with stable vitals. She was alert and oriented to time, place, and person and had clear cohesive speech. Her ophthalmic 
Table 1: Barrow's classification of CCF

\begin{tabular}{ll}
\hline Type & Angio-architecture \\
\hline Type A & $\begin{array}{l}\text { Direct communications between the internal carotid } \\
\text { artery and the cavernous sinus }\end{array}$ \\
Type B & Dural ICA branches to the cavernous sinus \\
Type C & Supplied solely by the dural branches of the ECA \\
Type D & Dural ICA and ECA branches to the cavernous sinus \\
\hline
\end{tabular}

examination revealed left-sided ptosis with restriction of adduction, elevation, and depression of the left eye. She also had diplopia. Pupils were round and reactive to light and the conjunctiva was clear. Left anterior segment examination was essentially normal. No facial asymmetry was elicited, the tongue was in midline, and the shoulder shrug was intact bilaterally. Left cranial nerve VI examination was normal. The rest of her physical examination revealed no sensory-motor compromise with intact coordination.

Her computerized tomography (CT) scan from the outside hospital, which was completed the week prior, revealed a closed skull fracture, subarachnoid hemorrhage, possible arachnoid cyst, and right orbital fracture extending through sella turcica (Fig. 1).

A diagnosis of pupil sparing cranial nerve III nerve palsy was made. Additional intracranial imaging was ordered, including an magnetic resonance imaging/magnetic resonance angiography (MRI/MRA) to rule out carotid artery dissection. MRI of the brain revealed a basilar skull fracture, left ICA pseudo aneurysm, and carotid-cavernous fistula (Fig. 2).

Following recognition of the CCF, the patient underwent a successful transarterial right ICA angiogram and balloon-assisted coil embolization of left CCF under general anesthesia with electroencephalography (EEG) monitoring (Fig. 3). The patient tolerated the procedure well and was transferred to the trauma ICU for neuromonitoring in stable condition. After the endovascular treatment of her CCF, the patient's neurological symptoms resolved.

\section{Discussion}

Traumatic CCFs, are exclusively type A, occur most commonly as a result of basilar skull fractures. While not commonly diagnosed, one retrospective study showed an overall incidence of $3.8 \%$ for traumatic CCF in patients with basilar skull fractures, with an incidence of $8.3 \%$ in middle fossa fractures. ${ }^{4}$

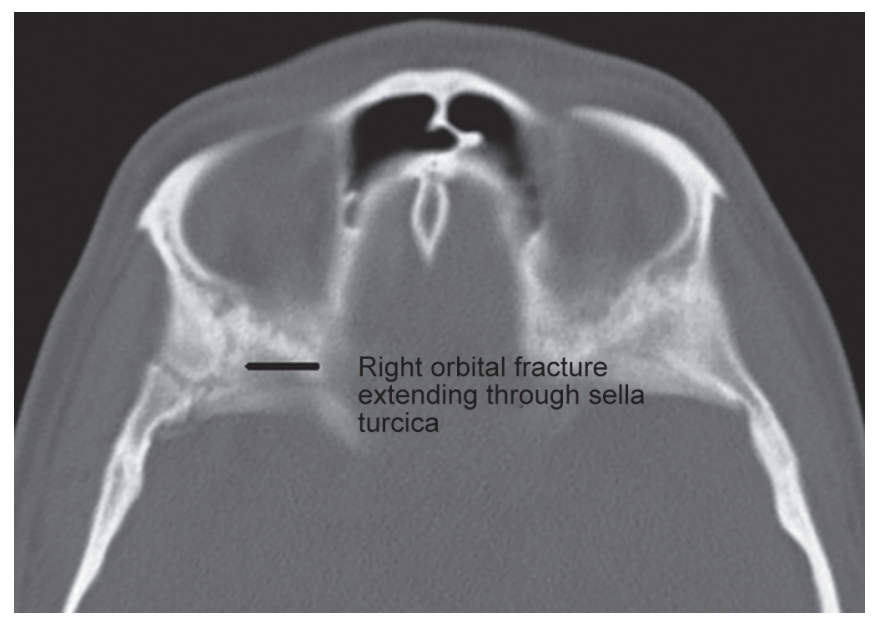

Fig. 1: Right orbital fracture extending through sella turcica

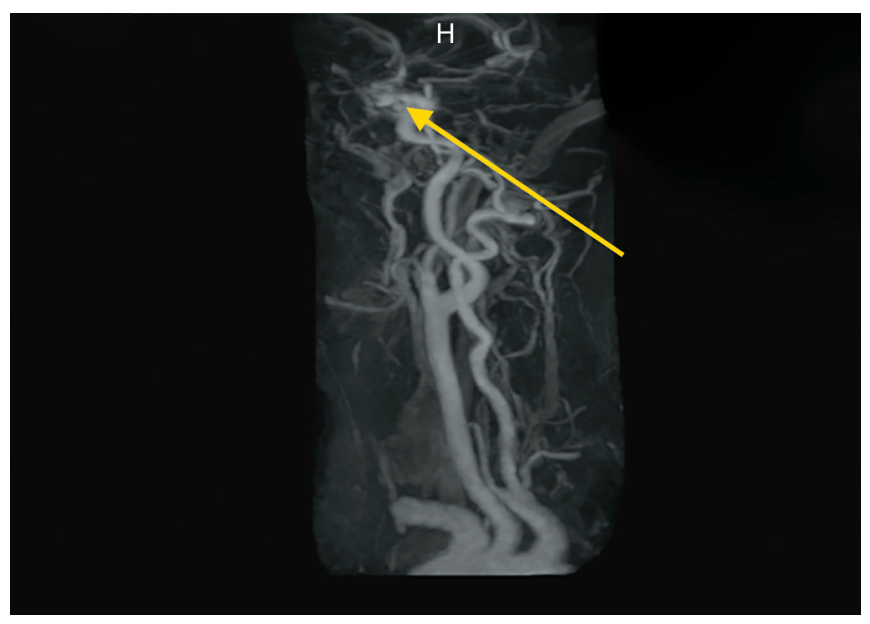

Fig. 2: MRA suspicious for CCF (yellow pointer)

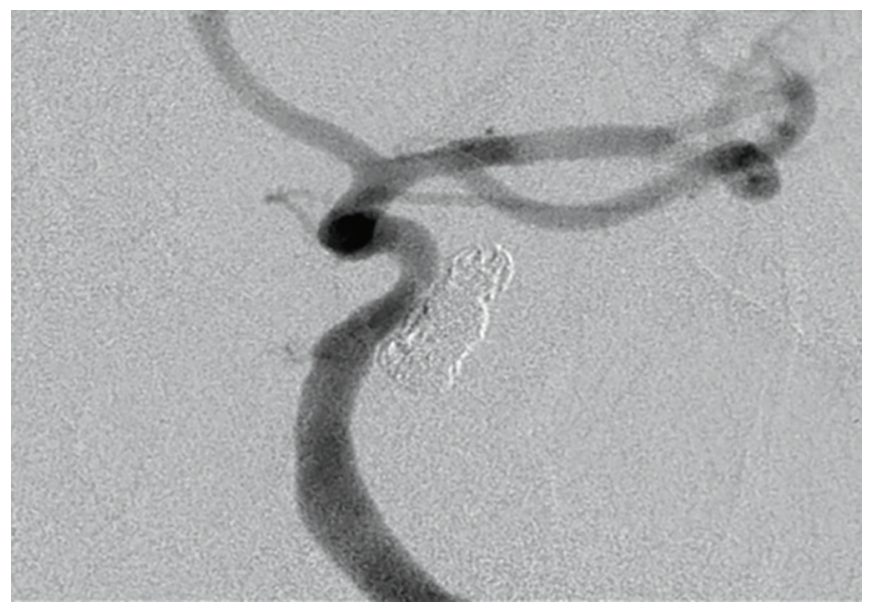

Fig. 3: Completion angiogram view after coil embolization of CCF

The pathophysiologic changes responsible for clinical symptoms are that CCF allows highly pressurized arterial blood to be transmitted directly into the cavernous sinus and the draining veins, leading to venous hypertension. This high-pressure "revised" venous drainage of fistula heads toward the ophthalmic venous system anteriorly; the superior petrosal sinus, or the basilar plexus posteriorly; the sphenoparietal sinus laterally; the intercavernous sinus contralaterally; the pterygoid plexus via the vein of the foramen rotundum and the vein of the foramen ovale inferiorly. 5,6

The classic presentation for a patient with a direct, high-flow CCF is the sudden development of Dandy's triad: exophthalmos, bruit, and conjunctival chemosis. The complete triad may not always be found. However, most patients do present with proptosis (90\%), chemosis (90\%), diplopia (50\%), cephalic bruit (25\%), pain (25\%), trigeminal nerve dysfunction, elevated intraocular pressure, and visual loss (up to $50 \%$ ). ${ }^{7}$ One of the most feared complications of traumatic CCF is visual loss. ${ }^{8}$ While many of the other neuro-ophthalmologic symptoms are relieved with obliteration of the fistula, visual loss, particularly with loss of light perception, can persist, making early recognition and treatment of traumatic CCFs critical. ${ }^{9}$ Similarly as described above, our patient also had left-sided ptosis with restriction of extraocular muscle movement along with diplopia. The differential diagnosis of traumatic CCF is vascular lesions such as arteriovenous malformation and cavernous sinus thrombosis. ${ }^{10}$ 
While CCFs are able to be seen on CT/computer tomography angiography (CTA), MRI/MRA, and transcranial ultrasounds, the gold standard for diagnosis of CCF is cerebral angiography. Evidence of cavernous sinus enlargement, proptosis, extraocular muscle enlargement, superior ophthalmic vein dilation, or dilation of cortical or leptomeningeal vessels, as well as associated skull fractures, may be seen on CT or MRI and are suggestive of CCF. ${ }^{11}$ However, the absence of abnormalities on noninvasive imaging studies does not exclude the diagnosis of CCF. The initial angiographic evaluation can be used to obtain the size and location of the fistula, differentiation of direct from indirect lesions, presence of any associated cavernous carotid aneurysm, venous drainage patterns determination of therapeutic route, and identification of any dangerous collateral pathways. Identification of these features will allow for the usage of the most appropriate treatment method. ${ }^{12}$

The goal of the treatment is to occlude the treatment site, which can be done in a variety of ways. There are certain high-risk features which were identified by Halbach after his study on 155 patients with CCF. They comprise of a pseudoaneurysm, large varix of the cavernous sinus, venous drainage to cortical veins, and thrombosis of other venous outflow pathways distant from the fistula. ${ }^{13}$ Treatment modalities include conservative management (medical management and compression therapy), endovascular repair, stereotactic radiosurgery, and surgical management. Highrisk fistulas are treated with interventional approach, and low-risk lesions with mild symptomatology are managed conservatively. Patients with low-risk lesions are reassured, educated regarding potential changes in symptoms, and allowed time for potential spontaneous closure of the fistula. ${ }^{14}$

The first-line treatment for high-flow CCFs is endovascular embolization through transarterial or transvenous access with the use of metal coils. ${ }^{15}$ In our patient, we employed transarterial right ICA approach to perform balloon embolization which is most commonly used.

Other endovascular approaches used to treat direct CCFs include detachable balloon occlusion and deployment of a covered stent across the fistula. The role of surgical management is limited due to associated morbidity from cranial nerve deficits and residual fistulous communications. Open surgical intervention should be performed in cases where endovascular treatment is not possible or is unsuccessful.

\section{Conclusion}

Our case presentation highlights the importance of having a high index of suspicion for CCFs in trauma patients with basilar skull fractures. High-flow fistulas, categorized as type A, are most likely to result from such traumatic events. ${ }^{16}$ These CCFs, which are direct shunts between the ICA and cavernous sinus, can lead to significant neuroophthalmologic abnormalities. Successful and timely endovascular coil embolization of CCF can prevent development of disabling sequela, such as complete visual loss, and provide relief of symptoms. The key to this success of endovascular approach is tailoring to individual cases according to the type, anatomy, and extent of each fistula. ${ }^{17,18}$

\section{References}

1. BarrowDL,SpectorRH, etal.Classification and treatment of spontaneous carotid-cavernous sinus fistulas. J Neurosurg 1985;62:248-256. DOI: 10.3171/jns.1985.62.2.0248.

2. Pülhorn $\mathrm{H}$, Chandran $\mathrm{A}$, et al. Case report: traumatic carotid-cavernous fistula. J Trauma Nurs 2016;23:42-44. DOI: 10.1097/jtn.00000000 00000174.

3. Kaplan JB, Bodhit AN, et al. Communicating carotid-cavernous sinus fistula following minor head trauma. Int J Emerg Med 2011;5:1-5. DOI: 10.1186/1865-1380-5-10.

4. Ke L, Yang Y, et al. Bilateral carotid-cavernous fistula with spontaneous resolution: a case report and literature review. Schaller B, editor. Medicine 2017;96(19):e6869. DOI: 10.1097/md.0000000000006869.

5. Tjoumakaris $\mathrm{SI}$, Jabbour PM, et al. Neuroendovascular management of carotid cavernous fistulae. Neurosurg Clin N Am 2009;20:447-452. DOI: 10.1016/j.nec.2009.07.013.

6. XuX-Q, Liu S, et al. Follow-up of 58 traumatic carotid-cavernous fistulas after endovascular detachable-balloon embolization at a single center. J of Clin Neuro 2013;9:83-90. DOI: 10.3988/jcn.2013.9.2.83.

7. Tan AC, Farooqui $S$, et al. Ocular manifestations and the clinical course of carotid cavernous sinus fistulas in Asian patients. Orbit 2014 Feb;33(1):45-51. DOI: 10.3109/01676830.2013.851253.

8. Razeghinejad M-R, Tehrani MJ. Sudden Onset and Blinding Spontaneous Direct Carotid-Cavernous Fistula. J Ophthalmic Vis Res 2011;6(1):50-53.

9. Chaudhry IA, Elkhamry SM, et al. Carotid Cavernous Fistula: Ophthalmological Implications. Middle East Afr J Ophthalmol 2009;16(2):57-63. DOI: 10.4103/0974-9233.53862.

10. Oestreicher JH, Frueh BR. Carotid-cavernous fistula mimicking Graves' eye disease. Ophthalmic Plast Reconstr Surg 1995;11:2. DOI: 10.1097/00002341-199512000-00002.

11. Dos Santos D, Monsignore LM, et al. Imaging diagnosis of dural and direct cavernous carotid fistulae. Radiologia Brasileira 2014;47(4):251255. DOI: 10.1590/0100-3984.2013.1799.

12. Chen CC-C, Chang PC-T, etal.CT angiography and MRangiography in the evaluation of carotid cavernous sinus fistula prior to embolization: a comparison of techniques, AJNR Am J Neuroradiol 2005;26(9):23492356.

13. Halbach VV, Hieshima GB, et al. Carotid cavernous fistulae: indications for urgent treatment. AJR Am J Roentgenol 1987;149:587-593. DOI: 10.2214/ajr.149.3.587.

14. Debrun GM. Angiographic workup of a carotid cavernous sinus fistula (CCF) or what information does the interventionalist need for treatment? Surg Neurol 1995;44:75-79. DOI: 10.1016/0090-3019(95)00162-x.

15. Korkmazer B, Kocak B, et al. Endovascular treatment of carotid cavernous sinus fistula: a systematic review. World J Radiol 2013;5(4): 143-155. DOI: 10.4329/wjr.v5.i4.143.

16. Ringer AJ, Salud L, et al. Carotid cavernous fistulas: anatomy, classification, and treatment. Neurosurg Clin N Am 2005;16:279-295. DOI: 10.1016/j.nec.2004.08.004.

17. Yu S, Lee S, et al. Traumatic Carotid-Cavernous Sinus Fistula in a Patient with Facial Bone Fractures. Arch Plast Surg 2015;42(6):791-793. DOI: 10.5999/aps.2015.42.6.791.

18. Liang W, Xiaofeng Y, et al. Traumatic Carotid Cavernous Fistula Accompanying Basilar Skull Fracture: A Study on the Incidence of Traumatic Carotid Cavernous Fistula in the Patients with Basilar Skull Fracture and the Prognostic Analysis About Traumatic Carotid Cavernous Fistula. J Trauma 2007;63(5):1014-1020. DOI: 10.1097/ ta.0b013e318154c9fb. 